SIR,-May I add a few notes to the reply to the inquiry concerning pain in phantom foot ("Any Questions?" April 24, p. 817)? French statistics show that $72.5 \%$ of all amputees, at least, complain of pains, most of them being phantom pains (personal statistics).

In 1938 I established that such pains are greatly relieved with parenteral thiamine in a very high proportion of cases. When this quite easy method fails to give relief we perform a sympathetic ganglia "novocain " block or a periarterial injection of novocain. Intra-arterial administration of the drug sometimes relieves the pain immediately and suppresses the phantom limb sensations. At the next stage we proceed with lumbar or cervical sympathectomy, advisable in cases in which the block gives only transitory relief. The surgical treatment of the main sensitivity route (excision of the terminal neuroma, radicotomy, cordotomy) is performed in cases of failure of the above-mentioned more conservative methods.

Recently some authors claimed the success of excision of the cortex, but their trials seem to remain merely in an experimental stage. Lately, psychotherapy has been introduced in the treatment of this very refractory condition.-I am, etc.,

Paris. A. Sllosberg, Consulting Physician of the Féderation des Amputés de Guerre de France.

\section{Tetanus Neonatorum}

SiR, - The two cases of tetanus neonatorum recorded by Drs. C. A. St. Hill and H. Lederer (May 22, p. 980) lead me to report the following:

On May 14, 1948, there came to my clinic a young man, aged 21, complaining of pain in the front of the left thigh which had been present from infancy; he said he rarely went a week without it. $\mathrm{He}$ had been called up at 18 for military service and had been graded $\mathrm{A} 1$ and served his full time. He was accompanied by his mother, who told me that he had been under my care in the Lincoln County Hospital when aged 12 days, with tetanus.

I immediately remembered the case, for it was most remarkable. I looked up the notes, but unfortunately they were scanty. He was born at full term, and breast fed until 7 days old, when his jaw was "locked" and he could not suck; he had had nothing for the 5 days prior to admission. Temperature was $104^{\circ} \mathrm{F}$. $\left(40^{\circ}\right.$ C. $)$. He was wasted and profoundly dehydrated. Every muscle was in extreme tonic spasm, and the legs were crossed in extension. He could be held in any position, the head, back, and limbs being perfectly rigid. Placed on the palm of one's hand he was like a piece of board. He remained in this condition for about three weeks and then began to recover, often having appeared on the point of death. The stump of the cord was septic as well as the prepuce. He was fed by nasal tube and later with a dropper. 800 units of A.T.S. were given intrathecally. The C.S.F. was clear and not under pressure.

On May 14, 1948, he appeared a healthy young man with a slightly waddling gait. He was working as an apprentice electrician. My examination revealed nothing to account for the pain ; in particular his C.N.S. was not abnormal. I referred him to my colleague, Mr. E. J. Bilcliffe, orthopaedic surgeon, and he reports as follows : "Marked loss of power in his left quadriceps, and can barely hold his leg from the couch; some limitation of movement of left hip." $X$ rays of both hips show marked coxa vara, with considerable shortening of necks of both femora and very shallow acetabula. The coxa vara on the left side is more pronounced than on the right. Is the tetanus a factor in the cause of the condition ?-I am, etc.,

Lincoln.

H. Cecil Barlow.

\section{Inserting Needle for Local Analgesia in Dentistry}

SIR,-To minimize the pain of inserting the needle into the gums we have a number of analgesics for surface application at our disposal, but we cannot depend on surface application alone because of its insufficient penetration, and the technique of inserting the needle has to be added. Already in my time as assistant it was my aim to make the dreaded insertion of the needle as humane as possible. Guided by this principle, I soon found that only the insertion of the needle at absolute rightangles to the injection surface brought favourable results. The reason for this is that the skin remains in its place and not stretched away by the pull or pressure of the needle. By injec- tions for extractions of teeth, although it may not always be possible to place the needle in at right-angles, one can follow the described principle as far as it is possible.

This process-with the exception of palatinal injections-is done in three phases. The first phase is the short and quick insertion of the sharp needle into the skin. The second phase consists in bringing the needle almost into line with the skin. During the third phase the needle is by constant flow of analgesic brought slowly to the position where the injection fluid is to be discharged. All injections which are easily accessible can be done according to the described three-phase system from "vestibulum oris" with the mouth not being much opened. According to requirements the teeth can also be completely closed. Awkwardly accessible are the injections in the lower jaw from "cavum oris." One is here compelled to follow the described principle as much as possible.

For the extraction of the lower molars the "endosteal " injection method is more to be recommended, and I refer here to my publication "Das endostale Injektionsverfaren zur Extraktion unterer Molaren," in Schmerz-Narkose-Anästhesie, Leipzig, 1937, vol. 1, and Folia Stomatologica (Zagreb), 1939, Part 1.

Before writing down these small points about the injection technique in the sphere of dentistry, the thought came spontaneously to me that any pain-reducing measures, however small, should be made available to the practitioner. The fact that on the publication of my article on the same theme in 1943 in the organ of the Bulgarian Odontological Federation, Sofia, the editor of the Zahnärztliche Rundschau, Sofia, made a footnote of appreciation expressing his pleasure in printing this work, shows for me that I followed the correct course.-I am, etc.,

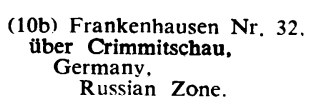

JACOB Vianden.

\section{The Problem of Caries}

SIR,-Mr. J. F. Volker (May 22, p. 1000) suggests that the most unsatisfactory aspect of dental caries research is unscientific criticism by medical colleagues and explains this attitude as resistance to new ideas. This seems a superficial view of the unsatisfactory state of medical knowledge and opinion.

First, there is nothing new in the idea that caries is the result of acid fermentation of food residues, and that sugar is especially responsible has been recognized for centuries. Recent dental research has not done much more than slowly accumulate piecemeal experimental evidence of what was already obvious from general observa-
tions of diet and dental disease.

Secondly, the problem of caries is not its histopathology, which is now fairly well understood, but the practical and sociological problem of its prevention. Doctors, in Britain at least, have done as much to solve this problem as dentists. The names of Drs. Harry Campbell, James Wheatley, and R. A. Lyster come to mind, and of course Dr. J. Sim Wallace, who is a dentist as well. How can doctors, without formal training in dental pathology, be expected to appraise adequately the voluminous and confusing literature on dental disease? A great part of this is itself unscientific and some of it is frankly antiscientific.

The medical profession might be blamed for completely handing over to dental surgeons responsibility for dental health, instead of merely delegating dental surgery to them. The dental profession, having gained independence, is much more to be blamed for failing to inform the medical profession and the public in a coherent way how dental disease should be prevented. Volker mentions the repeated experimental proof that fluorine applications reduce caries by $40 \%$ in American children. English dentists are simply incredulous; they scarcely seem to distinguish between this completely substantiated claim and the vague, exaggerated, or unsubstantiated claims made for vitamin $\mathrm{D}$, calcium, or humus-grown vegetables! Whose fault is this? Surely not our medical colleagues'?

While research has shown that the defects of modern diet which are responsible for caries are not, in the main, nutritional deficiencies, yet the country's diet is planned for health on purely nutritional considerations. The B.M.A. has appointed a nutrition committee ; could it not invite the B.D.A. to assist it with an authoritative statement on the dietetic prevention of dental disease? Collaboration of this sort in the U.S.A. has been very fruitful.-I am, etc.,

London. N.W.6.

R. B. D. STOCKER. 